\title{
Analysing the Politics of African State Policy: Some Thoughts on Robert Bates' Work
}

\author{
Manfred Bienefeld
}

It is almost five years since Robert Bates published Markets and States in Tropical Africa: the Political Basis of Agricultural Policies, ${ }^{1}$ in which he sought to explain the existence of widespread discrimination against peasant producers in Africa. As Africa's crisis has deepened, his analysis has attracted widespread attention both among academics and policy-makers, not least because it appears to provide a refreshingly clear and simple view of a complex and hitherto much neglected problem. The fact that it happens to reach conclusions that support arguments now fashionable in World Bank/IMF circles ${ }^{2}$ has naturally reinforced its popularity and significance.

This brief paper will examine the analysis presented in that book, since it remains the most accessible and comprehensive statement of Bates' position. It will argue that, although Bates has drawn welcome attention to political issues that have been ignored too often by economists and others, the clarity and simplicity of his conclusions largely reflect the fact that many of the most intractable sources of complexity have been excluded from consideration in various ways. Once reintroduced, these issues undermine those conclusions and destroy the deceptive simplicity of the argument, forcing the discussion back onto the familiar terrain of political economy, with all its ambiguities and uncertainties. Indeed, judged within that context, it is not clear that the analysis has advanced our understanding of the politics of Africa's policies.

Even so, there can be no doubting the importance of the issues that Bates has chosen to address, nor of the

\footnotetext{
- All page references are to this book as published by University of California Press, Berkeley in 1981.

2 The two recent reviews of Africa's problems published by the World Bank in 1981 and 1984 are both dominated by the view that subSaharan A trica's problems are primarily domestic and are largely resolvable by a domestic realignment of forces. See IBRD, 1981 , Accelerated Development in sub-Saharan Africa: An Agenda for Action (The 'Berg' Report), Report No 3358, Washington DC and IBRD, 1984, Toward Sustained Delelopmen in sub-Satharan Africa (The 'Please' Report), Washington DC.
}

interest and value of much of his empirically based discussion. In that sense his work is both topical and a welcome reminder that development is not a technical problem, but primarily a social and political one. Equally, the shortcomings of this particular attempt to analyse aspects of the political process, might serve as a warning to others who will follow in his footsteps.

It may appear unhelpful to suggest that the highly tentative and uncertain propositions of the political economy debate should be preferred to the crisp and clear conclusions offered by Bates, but that is exactly the suggestion made in this article. On past experience it may be important to stress that this article does not counterpose some alternative solution to that offered by Bates, but is concerned to evaluate the internal coherence and the underlying assumptions of his argument. Hence it does not argue that the political question is either unimportant or simple; on the contrary it suggests that it is vitally important and not nearly as simple as Bates suggests. Nor does it juxtapose the 'efficient' state to an 'inefficient' market; rather it challenges the proposition that, in the African context, a desirable politics is simply that which supports and facilitates responsiveness to market signals. Finally, it may be necessary to point out that the arguments put forward here cannot be countered by the charge that they do not offer a better explanation, although this is a depressingly common non sequitur. The article does not attempt to provide such an alternative, but merely considers the weaknesses in Bates' approach and suggests that if we are to improve our understanding of these issues, it will be necessary to confront them in their true and formidable complexity.

This note will consider, in turn: the problem being analysed; the approach to that problem; the factors that are effectively excluded from consideration; and, finally, the implications of these deficiencies for Bates' conclusions and for the more general debate. 


\section{The Problem Addressed by Bates}

Bates begins by noting Africa's agricultural failure, as reflected in the long term stagnation of per capita food production and of agricultural exports and suggests that ' $a$ consensus had emerged that the most important [impediment to agricultural growth] is the nature of the incentives offered to producers', and then suggests that 'it follows that the origins of the problem lie in the actions of those who distort the operations of the market' ( $\mathrm{ppl} / 2$ ). He then notes, with apparent surprise, that 'agricultural economists who stress the ineptness of government policy-makers often praise the acumen of persons in market operations' and promises to 'identify the source of this puzzling imbalance in human capabilities'. In this context he sets out to answer a far more ambitious question, namely: 'Why should reasonable men adopt public policies that have harmful consequences for the societies they govern?'

To this surprisingly and, one suspects, intentionally naive question he eventually gives the not very surprising answer that policy-makers behave in this way when it is in their narrow self-interest to do so. Once established, this proposition is then used to explain all manner of specific policies by identifying the groups whose narrow self-interest they are thought to serve.

This procedure is basic to most political economy discussions, and is reminiscent of those Marxist analyses that identify - or invent - endless numbers of 'petit bourgeoisies' to explain any and every twist and turn in public policy. However, for Bates, as for others, the value of such discussions depends on the definition of the underlying concepts. What is the public interest? What policies serve the public interest? What serves any group's or individual's self-interest? How does a group or individual distinguish between short and long-run interests? When does actual selfinterest diverge from perceived self-interest?

It is in seeking to answer these questions that any analyst, activist or politician confronts the greatest difficulties. Yet Bates makes short work of these problems, by retreating into a world where life is all too simple. The public interest is served by efficiency; efficiency is served by following the market; a group's self-interest lies in maximising its present income and power; short and long term interests do not diverge; and a group's perceived self-interest coincides with its actual self-interest. In this transparent, make-believe land, Bates pursues his quarry and inevitably reaches clear and simple conclusions. At least, he does so until the very end of the book, when he casually raises the possibility that a group may not act in its immediate narrow self-interest but, by then, it is too late to integrate this possibility usefully into the discussion, or to recognise that it undermines his entire argument.

\section{Bates' 'Approach' to the Problem}

In addressing the problem of agricultural policy, Bates begins by making it 'manageable', by reducing it to one of 'inadequate prices for agriculture' (where 'inadequate' is defined as diverging from world market prices). Henceforth the discussion can confine itself to the reasons why African governments might be so perverse as to systematically discriminate against rural producers in this inevitably undesirable way. Once he adds the assumption that groups invariably seek to maximise their short term material advantages, he is quickly led to the conclusion that this 'exploitation' of agriculture must be due to the fact that African governments are dominated by people whose narrow, short-term material interests are served by such exploitative policies, and whose survival in power must depend on their ability to use the resulting surplus to buy off elements of the losing groups. The people that best fit this description are variously identified as the industrial capitalists and workers, the bureaucracy or the 'urban dwellers'.

To these two basic determinants of govenment policy Bates adds a third, but apparently without realising the conflict this generates. Thus he also 'assumes throughout that political action is purposeful behaviour, and that among the major purposes of governments are the pursuit of certain social objectives'. Moreover, 'foremost among the social objectives ... is to shift the basis of their economies away from the production of agricult ural commodities and toward the production of manufactured goods' and this 'strongly influences their choice of agricultural policies' (pp3/4).

Unfortunately, the rest of the discussion never adequately explores the implications of this statement. $\mathrm{Had}$ it done so, it would have discovered the real difficulty of defining an optimal development strategy and the inadequacy of his crude assumption that any extraction of surplus from agriculture is contrary to the general interest. Nevertheless, this is combined with the equally crude assertion that those in the 'ruling coalition' are necessarily motivated by narrow, short-term interests, to suggest a variety of hypotheses regarding the likely degree and pattern of surplus extraction from agriculture. Chief among these are the following:

(i) Surplus extraction from agriculture will be more severe in poorer societies because the political importance of cheap food policies is relatively greater. 
(ii) Such extraction will be greater where rural producers are less powerful, and they will be less powerful where they are largely smallholders.

(iii) Surplus is easier to extract from export crops, since their marketing tends to be easier to control.

(iv) Surplus extraction is likely to be more intense when the economy has no access to surplus from other sources, such as minerals.

(v) When resources are channelled to the rural areas, this is done via 'projects' or discretionary subsidies which are favoured over higher producer prices because both can be directed to specific identifiable groups on a discretionary and sufficiently 'visible' basis to buy political support.

These propositions are of considerable practical interest, but their analytical significance is far less than the author supposes since they exclude the possibility that groups or individuals may take a longer or wider view of their self-interest or that some surplus extraction may be desirable and 'efficient', if certain structural changes are to be achieved. His failure to integrate these issues into the discussion is the more surprising since he explicitly acknowledges them as possibilities, although unfortunately only in passing.

Ultimately, the strength of the argument lies in its clear recognition that any technically desirable policy is no more than a hypothetical possibility, until it has obtained the support of some politically plausible coalition. While this represents an advance over wholly economistic approaches, it is no advance over the political economy debates which might be said to take this as their basic point of departure. Indeed, in relation to these, the argument appears rather simplistic and the lucidity and apparent clarity of its conclusions rests primarily on its exclusion of the most awkward issues. Once these are re-int roduced into the discussion, they soon remind us of the reasons why the conclusions of the political economy debate are invariably less elegant, less unambiguous and apparently less rigorous than those constructed in Bates' spurious laboratory conditions, created in his case, not by demagnetised vacuum chambers as in the natural sciences, but by a heuristic, make-believe world, protected against intrusions from the real world by conveniently framed assumptions. Unfortunately, the consequent clarity and rigour is obtained at an exorbitant price.

This is not to denigrate Bates' attempt to encourage development economists to acknowledge the importance of the political dimension. Nor is it to imply that the political economy debates have settled these issues, making further efforts redundant. Far from it. In fact, the problems raised by Bates' approach to these problems imply the need to go further, by integrating important, additional areas of real uncertainty into the discussion, because only then shall we come closer to understanding the real world. Unfortunately, we shall also find ourselves further removed from the beauty and simplicity of Bates' present conclusions.

\section{Excluded and Neglected Problems: Short versus Long-Term 'Efficiency'}

Bates' argument is centrally based on the assertion that 'efficiency' is adequately defined in terms of responsiveness to the world market's price signals. This is not a defensible position. Even the most ardent neo-classical economist must accept that the fashioning of an economy's future comparative advantage will require investments in infrastructure, industry, technology, education and many other areas, which cannot be adequately determined by current prices; whose "pay off will often be long deferred and obtained in the form of benefits that are not project specific and difficult to quantify; and which will be subject to a relatively high degree of uncertainty.

This is no minor objection. The moment it is recognised that systematic departures from current price signals are usually required to achieve 'long term efficiency', the complexity of the 'political problem' increases, because the 'optimal deviation' from market signals now becomes a matter for political definition, under conditions of uncertainty. Furthermore, the 'real world' will not easily tolerate the convenient fiction that the peasants' short term interests can always be equated with the 'general interest' or, to paraphrase Bates, with 'beneficial consequences for the societies of which they are a part'.

In Bates' own terms this quite simply means taking more seriously his assertion that governments are strongly influenced 'in their choice of agricultural policies' by their 'social objective' of transforming the economy by building a stronger non-agricultural sector. As he recognises when discussing the opportunities created by the presence of significant quantities of mineral wealth, such an objective would always require a shift of surplus between sectors. This would, of course, include agriculture, so that surplus extraction from agriculture is clearly not always contrary to the interests of society, nor even to the long term interests of the peasantry. This greatly complicates the definition of the political coalitions that would be required to avoid the implementation of public "policies that have harmful consequences for the societies they govern'.

This point becomes particularly telling when it is applied to agriculture itself. There is, in fact, little 
empirical evidence to show that total agricultural output, as opposed to the output of particular crops, is highly price elastic. Indeed, it is widely acknowledged that significant price responses will only be forthcoming if effective investment in infrastructure, research, marketing and information diffusion has preceded such price incentives.

Obviously, these arguments do not justify any degree of surplus extraction from agriculture, since excessive zeal on this front may induce marketed surpluses to fall so far that the higher rates of extraction actually yield lower total quantities of surplus, as in the socalled 'scissors crisis' of the Soviet Union in the 1930s. On the other hand, it does mean that any transfer of surplus from agriculture cannot simply be denounced as contrary to the 'social interest'. It also means that African states cannot solve this problem simply by adhering to world market prices in setting their domestic prices, even though there are many cases in Africa today where surplus extraction from agriculture has been excessive and where prices should probably be brought closer to those prevailing in the world market.

\section{Excluded and Neglected Problems: Policy Risks in the Real World}

Because Bates does not take the above issues seriously, he is unable to address the question of the differential risks associated with various policies or strategies. Once again his world is a simple place where resources are flexible and mobile and where different patterns of specialisation do not carry varying degrees of risk. Discrimination in favour of food crops is frowned upon as a legacy of the bad old order. The international market is treated as a 'given', whose vagaries need not be critically examined before African governments formulate agricultural policy. The ironic result is that, having roundly denounced the African elites for their stupidity in thinking that peasants could, or would, bear the burdens imposed by their hasty and ill-considered 'modernisation programmes', Bates now suggests that one should rely on those same peasants to 'do the job' of financing growth and development (and, apparently, of paying off accumulated debts), so long as they are given the largest possible share of the relevant international price. This in spite of the fact: that some of those prices have recently fallen so sharply that the farmers would now be getting less than they got five years ago, even if they were now to receive 90 per cent of the world market price; that the deterioration of infrastructure (especially of roads) and of capital equipment (especially lorries) has raised the actual costs of marketing dramatically in the meantime; and that the relative debt burden being carried by these economies has grown explosively and has to be carried in foreign exchange, financed from primary exports.

Bates' inability to deal sensibly with the problem of uncertainty, given his assumptions, is reflected most clearly in his summary of Africa's dismal experience with its development projects, when he writes:

To increase output, governments finance production programs. But in doing so, they introduce characteristic distortions. Given the level of resources devoted to the programs, for example, they often create too many projects; the programs then fail because the resources have been spread too thin. Such behaviour is nonsensical when analyzed solely in terms of stated objectives...(p5).

Like all the others, this 'paradox' is resolved by being shown to be the result of political calculations based on the short-term interests of the immediate actors. Yet, while these are clearly significant, this is a nonsensical way of depicting the issue, because it implies that these decisions were non-problematic, factual decisions made by certain local groups in accordance with their unambiguous, narrow selfinterest, rather than being decisions subject to high risk or uncertainty. It can not have escaped notice that the point in the 1970s when the largest proportion of Africa's development projects suddenly ceased to be viable coincided with the onset of a severe global recession and an unprecedented rise in energy prices, followed by a steep increase in international interest rates and a sharp decline in the prices of most of Africa's commodity exports. Surely this 'coincidence' deserves some comment and thought, as regards the risks borne by very poor economies integrating themselves rapidly into a volatile international economy, when they have little margin for error and relatively little resource flexibility. Certainly it is unrealistic to suggest that the relatively general failure of Africa's development projects can simply be presented as a result of obviously 'nonsensical' decisions that can only be explained in terms of the political interests they served, as if their actual outcome had been intended and forseeable and as if each project had not been ratified as 'viable' by technical experts from abroad. In fact, both in the future, as in the past, all such decisions will require difficult judgements and will always be subject to high levels of uncertainty. Moreover, if things are to change significantly, they will have to be taken by political coalitions prepared (or induced) to take a longer term view of their "consequences for the societies they govern' (Bates) and to take full account of the attendant risks from that perspective. This is the real political task. It is far more complex than that presented by Bates, and the latter's analysis and conclusions do nothing to clarify the need for, or to 
facilitate the accomplishment of that task. Indeed they constitute an obstacle to both of these objectives.

\section{Excluded and Neglected Problems: The International Dimension}

The last point already draws attention to the devastating 'omission' of the international dimension from Bates' argument. The rationale offered for it is highly revealing and deserves to be cited at length. Bates differentiates his contribution from that group of political economists who 'share a common conviction: that patterns of change in Third World countries are largely determined by international political and economic forces', by arguing that:

It is clear enough, of course, that major forces affecting the prosperity of Africa have originated in the developed nations; the depression of the 1930s and the boom of the 1950s are the most vivid examples. But it is less well understood that African states strongly influence the specific ways in which these forces affect them. They do so out of regard for their own needs and the needs of powerful interests within their own societies. Furthermore, as I will show, the ways in which they manipulate these forces create enduring patterns of advantage within the emergent social order of Africa. This study therefore joins the work of others in arguing that to understand the patterns of development in Third World nations, scholars should pay more attention to the capacity for autonomous choice on the part of local actors, both public and private, and give greater weight to the importance of these choices in shaping the impact of external environments upon the structure of local societies [Bates 1981:8].

As it stands this statement appears unobjectionable, but Bates actually uses it to exclude the international dimensions, as if those internal forces could be analysed and understood separately from external pressures; and as if the African state were an autonomous, local institution dealing with, and being influenced by, various external pressures. In spite of this extraordinary procedure, he suggests that his work shares the same basic approach as that of Alavi and Saul, but this is surely based on a misunderstanding. Certainly Alavi and Saul, and many others writing in the political economy tradition, have struggled to move beyond the crude external determinism that has characterised some contributions to this debate, but this has led them quite properly to attempt an integration of those internal and external forces. Nothing but confusion can be sown by this attempt to analyse Africa's 'internal' political forces in isolation.
In a seminar at IDS, Bates clarified his position on this point. Asked why he had chosen to exclude external influences on the domestic political scene, he answered that he felt that he had had to choose between emphasising the internal or the external dimension of the problem, and that he had decided to choose the internal because he did "not like Africans being presented merely as passive victims of international forces'. This most unsatisfactory answer confirms that Bates sees these as 'alternatives', to be chosen a priori by the analyst. If that appears hardly credible, it is nonetheless borne out by the discussion in this book. Even his policy conclusions are drawn without explicit consideration of these 'external factors' which, one can only assume, are thought to have no bearing on the kinds of policies that would be deemed to be in the 'general interest' or the kind of political coalitions that might be needed to support them.

This omission is fundamental. There is no way that the internal coalitions of Africa could be analysed without considering the role of foreign investors, of aid donors, of the international agencies and of the pressures emanating from the real (as opposed to the hypothetical) international market. These external forces are not necessarily dominant, but they are important and their influence increases as the African economies become more acutely dependent on external credit for survival. If they are excluded, the resulting picture must be seriously distorted and policy recommendations made on such a basis could be sensible only by accident.

The effect of this omission, whether calculated or not, is to eliminate the possibility that, far from being the rational and efficient 'alternative' market forces might actually be generating or reinforcing some of those problematic 'political pressures'. This would destroy the brilliant simplicity of the assertion that, "if the basic problem of farming in the developing countries is improper incentives for farmers ... then it follows that the origins of the problem lie in the actions of those who distort the operations of the market'. Moreover, once it is accepted that "policies that have beneficial consequences for the societies they govern' will often require some systematic and nationally defined deviation from international market signals, then the demand for 'static efficiency' that finds expression through the firms, the individuals and the agencies that use international price signals as their reference point, would itself constitute a major problem - the more so if the main actors in the international market have the power to manipulate prices, interest rates and exchange rates in their own interests. Even if such external pressures are not dominant, they unquestionably represent important, systematic influences on Africa's politics and policies. 


\section{Conclusions}

Just how important these various excluded factors are will vary over time and space. Certainly those 'internal' factors that are highlighted by Bates will generally prove to be important, but in every case their impact will be inextricably intertwined with these other factors. In the final analysis, the greatest challenge facing African societies is that of creating stable political coalitions able to define and to sustain policies that serve their 'general interest', in a difficult, hostile and uncertain international environment. The greatest failing of Bates' analysis is that it totally obscures this central issue because it isolates internal from external factors and assumes, in good neoclassical fashion, that the world market serves equally the global, the national and the individual interest.

To summarise, it is suggested that Bates' general argument is deeply flawed because it is based on indefensible assumptions that exclude important questions. As a consequence, the conclusions are both inadequate and misleading. However, even if one accepts the underlying premises of his argument, it suffers from a number of serious problems in its internal logic.

Bates has argued that efficiency and the social interest, as defined by him, requires: that farmers should be paid world market prices; that African farmers have been paid less than this; and that this 'must be' due to the fact that other interest groups have used their power to serve their narrow sectional interests, at the expense of the peasants and of society as a whole. He then concludes, quite naturally, that it is essential to 'let farmers into the ruling coalition', if things are to improve.

However, this poses a problem that is not adequately resolved. Elsewhere Bates argues that the political influence of farmers is generally greatly enhanced, if there are some relatively wealthy, large farmers who can command political attention because they wield economic power. However, he acknowledges that these wealthy farmers may themselves be members of the anti-peasant or anti-agriculture coalition; equally, in other cases, they may be the most effective spokesmen in defence of genuine agricultural interests. Unfortunately, little is said about the factors that might determine this outcome. In fact, the implication that 'farmers' do have some general common interest is not adequately explored, given its fundamental significance to the argument. In the absence of that discussion, the conclusion that more power should be given to 'farmers' cannot be considered very helpful.
This point would be reinforced if it were acknowledged that a united, undifferentiated body of 'farmers' may demand 'more than their share' (i.e. subsidies) if they held power, and that the resulting high prices might be used to protect them against the need to seek enhanced productivity through improved techniques of production. Once this is acknowledged, it is clear that the real implication of Bates' argument is not that power should go to 'the peasants', but that it should go to those whose interest lies in enforcing adherence to world market prices. It merely so happens that in many African countries, peasants presently have an interest in pushing producer prices closer to world market prices. However, analytically this is a mere coincidence and no-one should be misled into thinking that there is, therefore, a fundamental coincidence of interests between the peasantry of Africa and international finance. The fact that the two may be pulling in the same direction on this issue at this particular moment, is hardly an adequate basis for such a conclusion.

A second problem is revealed when Bates extols the virtues of mineral revenues as a source of investible surplus and suggests that this would ease the pressure on agriculture. His argument takes little account of the previous discussion of agriculture - how 'rents could be extracted from mining' hardly considers the question of the 'political coalition' that would be needed for that to be possible; nor does it consider the possibility that a 'scissors crisis' could also occur in the mining sector, in that if its margins were squeezed too hard, production might well fall more than proportionately. In fact Bates never explains why surplus extraction from this sector is treated as quite naturally beneficial. Given the rest of the discussion, this cannot be taken for granted. Moreover there is no reason to believe that a purely self-seeking elite would not simply add what surplus they could squeeze from agriculture to that which they could get from mining. Indeed, the trade-off that Bates assumes only arises if the surplus that is being extracted is intended for some limited purpose, such as the desire for structural change. Only then does it make sense to argue that if the surplus thus required can be obtained from minerals, then the pressure on agriculture would cease.

Finally, as indicated at the outset, right at the end of the book Bates makes the extraordinary statement that: 'Alternatively, in response to the erosion of advantages engendered by shortfalls in production, the dominant interests may be persuaded to forsake the pursuit of unilateral short-run advantage, and instead to employ strategies that evoke cooperation by sharing joint gains'. 
The reader is somewhat unprepared for this blow, which acts like a sudden self-destruct mechanism built into the last page of the text. The statement takes one right back to square one, undermining the entire argument that has gone before since, if that choice is always open to people - and to bureaucrats - and their behaviour is not governed by some self-evident, narrow self-interest, then choices become far more complex and uncertain and the problem of politics arises in a more realistic manner. In a manner, moreover, that would require a rather different type of analysis and that would undoubtedly suggest rather different conclusions.

Most significantly perhaps, Bates' recognition of the importance of 'joint gains' based on 'cooperation' necessarily implies the existence of some national rationality that must be counterposed to that of the global market. This clearly denies the validity of his use of international prices as adequate arbiters of efficiency, or his exclusion of the international dimension from the analysis of domestic political coalitions. Indeed, it confirms that the central political problem confronting Africa - and the rest of the developing world - is that of constituting a political coalition able to purse a national strategy capable of producing such 'joint gains', and of protecting that national rationality against the global rationality of international capital. In order to analyse that problem, one needs to start from this paragraph at the end of Bates' book; and one needs to work with different assumptions, different definitions and different concepts. 